ПЕРВЫЕ РЕЗУЛЬТАТЫ РЕГИСТРАЦИИ ИОНОСФЕРНЫХ ВОЗМУЩЕНИЙ ПО ДАННЫМ СЕТИ SIВNЕТ ПРИЕМНИКОВ ГНСС В АКТИВНЫХ КОСМИЧЕСКИХ ЭКСПЕРИМЕНТАХ

\title{
FIRST RESULTS OF REGISTERING IONOSPHERIC DISTURBANCES OBTAINED WITH SibNet NETWORK OF GNSS RECEIVERS IN ACTIVE SPACE EXPERIMENTS
}

\author{
А.Б. Ишин \\ Институт солнечно-земной физики СО РАН, \\ Иркутск, Россия, ishin@iszf.irk.ru \\ Н.П. Перевалова \\ Институт солнечно-земной физики СО РАН, \\ Иркутск, Россия, pereval@iszf.irk.ru \\ С.В. Воейков \\ Институт солнечно-земной физики СО РАН, \\ Иркутск, Россия, serg3108@iszf.irk.ru \\ В.В. Хахинов \\ Институт солнечно-земной физики СО РАН, \\ Иркутск, Россия, khakhin@iszf.irk.ru
}

\author{
A.B. Ishin \\ Institute of Solar-Terrestrial Physics SB RAS, \\ Irkutsk,Russia,ishin@iszf.irk.ru \\ N.P. Perevalova \\ Institute of Solar-Terrestrial Physics SB RAS, \\ Irkutsk,Russia,pereval@iszf.irk.ru

\section{S.V. Voeykov} \\ Institute of Solar-Terrestrial Physics SB RAS, \\ Irkutsk, Russia,serg3108@iszf.irk.ru

\section{V.V. Khakhinov} \\ Institute of Solar-Terrestrial Physics SB RAS, \\ Irkutsk,Russia, khakhin@iszf.irk.ru
}

Аннотация. Глобальная и региональные сети ГНСС-приемников много лет эффективно используются для геофизических исследований, причем число постоянно действующих приемников в мире неуклонно растет. В статье приводятся первые результаты использования новой региональной сети SibNet станций ГНСС в активных космических экспериментах. Сеть SibNet создана в Институте солнечно-земной физики (ИСЗФ СО РАН) в Южном Прибайкалье. Представлено подробное описание сети, характеристики используемых приемников, параметры антенн и способы их установки, приводится структура наблюдательных пунктов в целом, а также схемы покрытия радиотрассами региона действия приемника на широтах 50-55․ Показано, что выбранное расположение приемников позволяет регистрировать ионосферные неоднородности различного масштаба. Целью активных космических экспериментов было обнаружение и регистрация параметров ионосферных неоднородностей, вызванных воздействием струи реактивных двигателей космических кораблей серии «Прогресс». Использование метода картирования позволило обнаружить слабые высотно-локализованные ионосферные неоднородности и связать их с воздействием двигателей кораблей «Прогресс». Таким образом, показано, что развернутая сеть SibNet двухчастотных ГНСC-приемников в Южном Прибайкалье является эффективным инструментом мониторинга состояния ионосферы.

Ключевые слова: ионосфера, ГНСC, SibNet, «Прогресс».
Abstract. Global and regional networks of GNSS receivers have been successfully used for geophysical research for many years; the number of continuous GNSS stations in the world is steadily growing. The article presents the first results of the use of a new regional network of GNSS stations (SibNet) in active space experiments. The Institute of Solar-Terrestrial Physics of Siberian Branch of Russian Academy of Sciences (ISTP SB RAS) has established this network in the South Baikal region. We describe in detail SibNet, characteristics of receivers in use, parameters of antennas and methods of their installation. We also present the general structure of observation site and the plot of coverage of the receiver operating zone at $50-55^{\circ}$ latitudes by radio paths. It is shown that the selected location of receivers allows us to detect ionospheric irregularities of various scales. The purpose of the active space experiments was to reveal and record parameters of the ionospheric irregularities caused by effects from jet streams of Progress cargo spacecraft. The mapping technique enabled us to identify weak, vertically localized ionospheric irregularities and associate them with the Progress spacecraft engine impact. Thus, it has been shown that the SibNet deployed in the Southern Baikal region is an effective instrument to monitor ionospheric conditions.

Keywords: ionosphere, GNSS, SibNet, Progress.

\section{ВВЕДЕНИЕ}

Для исследования ионосферы в настоящее время широко применяют сети наземных приемников глобальных навигационных спутниковых систем (ГНСС), таких как ГЛОНАСС и GPS. Каждый приемник проводит одновременное слежение более чем за двумя десятками спутников ГНСС. Сопровождение сигналов от каждого спутника происходит минимум на двух 
независимых частотах, что позволяет по измерениям приемника рассчитывать вариации полного электронного содержания (ПЭС) в ионосфере. Таким образом, развертывание в регионе сети из нескольких десятков приемников обеспечивает возможность одновременного просвечивания ионосферы сотнями лучей спутник-приемник. Указанное преимущество, а также относительно невысокая цена и простота развертывания сети приводит к тому, что использование ГНСС в геофизических исследованиях оказывается целесообразным.

Отдельные плотные сети приемных станций ГНСC, например сеть GEONET в Японии, уже много лет широко используются в качестве разнесенного инструмента мониторинга состояния ионосферы. По данным таких сетей проводятся исследования реакции ионосферы на солнечные вспышки и затмения [Afraimovich, 2000; Liu, Lin, 2004; Afraimovich et al., 2007], геомагнитные бури [Perevalova et al., 2008; Shimeis et al., 2015] и мощные техногенные воздействия [Ding et al., 2014; Zherebtsov, Perevalova, 2016]. В последние годы большое внимание уделяется анализу мерцаний сигналов ГНСС [Prikryl et al., 2010; Jiao et al., 2013; Spogli et al., 2013], что позволяет получать информацию о параметрах мелкомасштабных ионосферных неоднородностей, приводящих к рассеянию радиосигналов и снижению качества радиосвязи. Результаты всех этих исследований, с одной стороны, помогают более детально разобраться в физике наблюдаемых явлений, а с другой, позволяют улучшать функционирование самих ГНСС: повышать точность определения координат, снижать вероятность сбоев и т. п. [Prikryl et al., 2010; Demyanov, Yasyukevich, 2011; Demyanov et al., 2012; Lejeune et al., 2012; Jiao et al., 2013]. Для сейсмоопасных регионов (в частности, для Байкальской рифтовой системы) важной прикладной задачей является также поиск откликов и возможных предвестников землетрясений [Сейсмоионосферные..., 2012]. Кроме того, совокупность всех сетей станций ГНСС может выступать в качестве всепланетного инструмента исследования околоземного космического пространства [Afraimovich et al., 2013]. Однако распределение приемников ГНСС по земному шару крайне неравномерно. Очень низка плотность ГНСС-сетей в России. До недавнего времени на большой территории Байкальского региона стабильно работали всего две станции ГHСC: BADG и IRKT. В 2012 г. в ИСЗФ СО РАН начато развертывание сети постоянно действующих двухчастотных приемников ГНСС.

В силу уникальных природных особенностей (оз. Байкал, система рифтовых разломов, высота над уровнем моря, большое число солнечных дней в году и др.) район Прибайкалья является крайне интересным для всестороннего исследования. Это определило создание в регионе развитого комплекса гелиогеофизических инструментов, на которых ведутся регулярные наблюдения Солнца, космической погоды, магнитного поля Земли, ионосферы [Сейсмоионосферные..., 2012; Институт..., 2015]. Сеть приемников ГНСС дополнила комплекс инструментов ИСЗФ СО РАН.
В 2009-2014 гг. с помощью этого комплекса [Институт..., 2015; Сейсмоионосферные..., 2012] (вблизи оз. Байкал), проводилась серия активных космических экспериментов (КЭ) «Радар-Прогресс» по регистрации ионосферных эффектов, вызванных включением сближающе-корректирующих двигателей (СКД) транспортно-грузовых кораблей (ТГК) серии «Прогресс» после отстыковки от международной космической станции (МКС). По согласованию с ИСЗФ СО РАН включение двигательной установки (ДУ) происходило при пролете ТГК над обсерваториями Института [Khakhinov et al., 2011, 2012; Борисов и др., 2012; Хахинов и др., 2010, 2012, 2013,]. ТГК этом был ориентирован так, что реактивная струя была направлена на наземные инструменты. Целью эксперимента было обнаружение и одновременная регистрация эффектов воздействия струи с помощью различных геофизических инструментов [Лебедев и др., 2014; Еселевич и др., 2016; Липко и др., 2016; Клунко и др., 2016; Белецкий и др. 2016; Шпынев и др., 2017]. Наряду с другими инструментами для регистрации эффектов работы двигателей ТГК использовалась и новая региональная сеть станций ГНСC (SibNet), создаваемая в ИСЗФ СО РАН. Описанию и первым результатам использования ГНСC-сети SibNet для обнаружения ионосферного отклика на работу реактивных двигателей ТГК «Прогресс» посвящена настоящая статья.

\section{CETb SibNet ПРИЕМНИКОВ ГНСС. ОПИСАНИЕ ПРИЕМНОГО КОМПЛЕКСА}

Для проведения комплексного непрерывного геофизического мониторинга ионосферы и определения динамических параметров неоднородностей ионосферной плазмы в районе Южного Прибайкалья развернута сеть постоянно действующих наблюдательных пунктов с приемниками сигналов ГНСС (сеть SibNet, рис. 1).

Из соображений сохранности оборудования, а также для организации непрерывного режима функционирования SibNet для установки приемников ГНСС были выбраны обсерватории ИСЗФ СО РАН. С одной стороны, взаимное расположение приемных

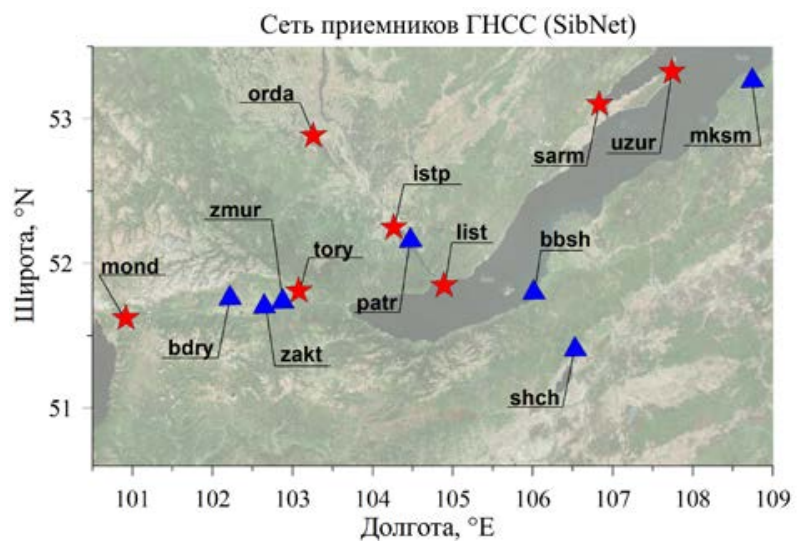

Puc. 1. Сеть наблюдательных пунктов с приемниками сигналов ГНСС в Южном Прибайкалье. Звездочками отмечены стационарные станции, треугольниками - временные 
станций выбиралось таким образом, чтобы охватить наблюдениями как можно больший регион. С другой стороны, расчет скорости и направления перемещающихся ионосферных возмущений (ПИВ) проводится с помощью метода GPS-интерферометрии [Афраймович, Перевалова, 2006]. Для эффективной работы указанного метода необходимо, чтобы станции ГНСС, регистрирующие вариации ПЭС, располагались в вершинах треугольников. При этом расстояние между приемниками не должно превышать половины длины волны исследуемого ПИВ. Расстояние между станциями ГНСС определяет масштаб ПИВ, скорости которых могут быть исследованы с помощью данной сети. Примеры измерительных треугольников с различными расстояниями между станциями приведены в табл. 1 .

Таблица 1

Некоторые измерительные треугольники, образованные станциями SibNet

\begin{tabular}{|c|c|c|}
\hline $\begin{array}{c}\text { Измерительный } \\
\text { треугольник }\end{array}$ & $\begin{array}{c}\text { Расстояние между } \\
\text { станциями, км }\end{array}$ & $\begin{array}{c}\text { Масштаб исследуе- } \\
\text { мых ПИВ, км }\end{array}$ \\
\hline MOND-ORDA-LIST & $212-160-275$ & более 600 \\
\hline ORDA-LIST-SARM & $160-192-241$ & более 500 \\
\hline ORDA-ISTP-TORY & $98-95-120$ & более 250 \\
\hline LIST-TORY-ISTP & $125-95-62$ & болеe 250 \\
\hline
\end{tabular}

В состав каждого наблюдательного пункта SibNet входят приемник ГНСC, управляющий компьютер, источник бесперебойного электроснабжения, канал передачи данных (рис. 2).

Станции SibNet оснащаются приемниками DeltaG3T и SigmaQ-G3D компании Javad GNSS (www.javad.com) [GREIS, 2010]. Оборудование Javad GNSS сертифицировано на территории РФ и внесено в реестр средств измерений (www.ugt.ur.ru).

Для приема радиосигналов ГНСС используются антенны RingAnt-G3T (http://www.javad.com/jgnss/ products/antennas), которые представляют собой антенны типа Choke Ring. Данные антенны обладают высокой точностью, встроенной защитой от многолучевости спутникового сигнала, высокой стабильностью положения фазового центра, а также обеспечивают минимальные частотные искажения.

С целью обеспечения возможности использования данных SibNet в геодинамических исследованиях антенны стационарных пунктов наблюдений устанавливаются на специально оборудованные бетонные реперы. Для минимизации влияния сезонных колебаний температуры и других локальных деформирующих факторов репер устанавливается на монолитные коренные породы, если их выходы имеются на территории обсерватории. Примером является станция UZUR Байкальской магнитотеллурической обсерватории ИСЗФ СО РАН (рис. 3). Если обсерватория находится на осадочных/наносных породах, железобетонный якорь репера опускается ниже глубины промерзания. Примером может служить репер, оборудованный на станции TORY Геофизической обсерватории ИСЗФ СО РАН (рис. 4, $a$, б). Глубина якоря для данного репера составляет 4.5 м. В некоторых случаях антенна приемника устанавливается на стену устоявшегося капитального строения с жесткой привязкой к капитальной стене. При- мер такого пункта - станция ORDA Обсерватории радиофизической диагностики атмосферы ИСЗФ СО РАН (рис. 4, в). Параметры всех постоянно действующих станций SibNet приведены в табл. 2. Указаны также характеристики временных станций, развернутых во время активных КЭ.

Для установки всех антенн в горизонтальное положение используются изготовленные в ИЗСФ СО РАН специальные устройства - «горизонтализаторы» (рис. 3, $а$, б). Благодаря тщательной установке антенн данные, полученные на сети SibNet постоянно действующих приемных станций ГНСС, могут быть использованы не только для диагностики поведения ионосферной плазмы, но и для наблюдений за подвижностью блоков литосферы, что существенно расширяет возможности сети.

Приемники Javad Delta-G3T и Javad SigmaQ-G3D обеспечивают одновременный прием сигналов всех видимых спутников систем ГЛОНАСC, GPS, Galileo, SBAS по 216 каналам. Приемники выполняют кодовые, фазовые и амплитудные измерения для перечисленных спутниковых систем. Приемники оснащены интерфейсами RS-232 и USB. B SigmaQ-G3D (пункт TORY) реализован многоантенный (три антенны) прием сигналов ГНСС. Это позволяет проводить исследования мелкомасштабной структуры ионосферы с разнесением радиотрасс на небольшое (порядка нескольких десятков метров) расстояние, но при этом осуществляя синхронный прием сигналов спутников. Трехантенный приемник SigmaQG3D может рассматриваться и как измерительный треугольник со сверхмалым расстоянием (порядка 20-30 м) между антеннами.

Модифицированные модели приемников DeltaG3T и SigmaQ-G3D, которые используются в ИСЗФ $\mathrm{CO}$ РАН, обеспечивают возможность измерения амплитуды сигнала с частотой до 50 Гц для изучения амплитудных мерцаний (амплитудные измерения). Под мерцаниями понимают флуктуации амплитуды, которые испытывают радиосигналы, проходящие через ионосферу. Ионосферные мерцания свидетельствуют о рассеянии сигнала на неоднородностях электронной концентрации в ионосфере и приводят к уменьшению отношения сигнал/шум, вызывающему сбои и снижение точности позиционирования. Запись амплитудных мерцаний дает возможность вести локальные наблюдения мелкомасштабных ионосферных возмущений и оценить точность навигационно-временного позиционирования.

Важным достоинством приемников компании Javad GNSS является открытый протокол обмена данными между приемником и компьютером. Описание команд приемника и формата внутренних файлов (бинарные файлы jps) приведено в документе GREIS (GNSS Receiver External Interface Specification), размещенном на официальном сайте компании www.javad.com [GREIS, 2010]. Это позволяет создавать собственные программы управления приемником, а также получать дополнительную информацию, которая обычно теряется при конвертировании внутренних файлов приемника в RINEX-формат (амплитуда, квадратуры сигналов и т. д.). С целью обеспечения автоматической работы приемников SibNet 

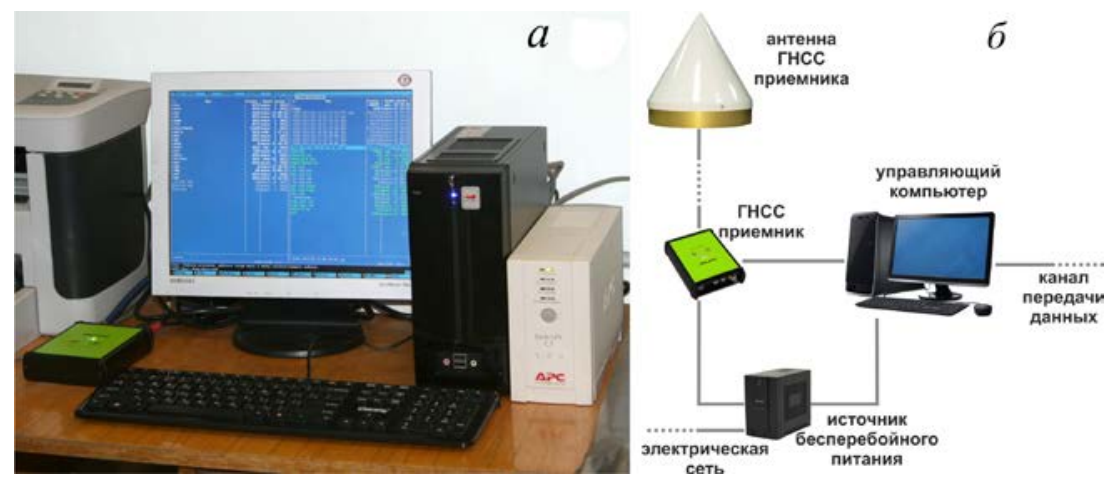

Puc. 2. Внешний вид (a) и схема (б) оборудования измерительного комплекса ГНСС, установленного на наблюдательных пунктах
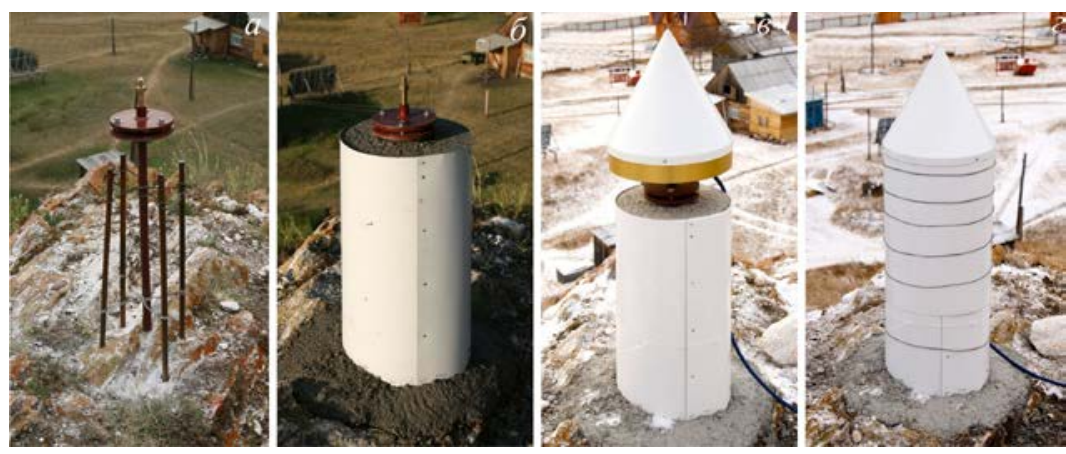

Puc. 3. Этапы установки антенны ГНСС на скальном основании в пункте наблюдения UZUR ( $a-\sigma)$

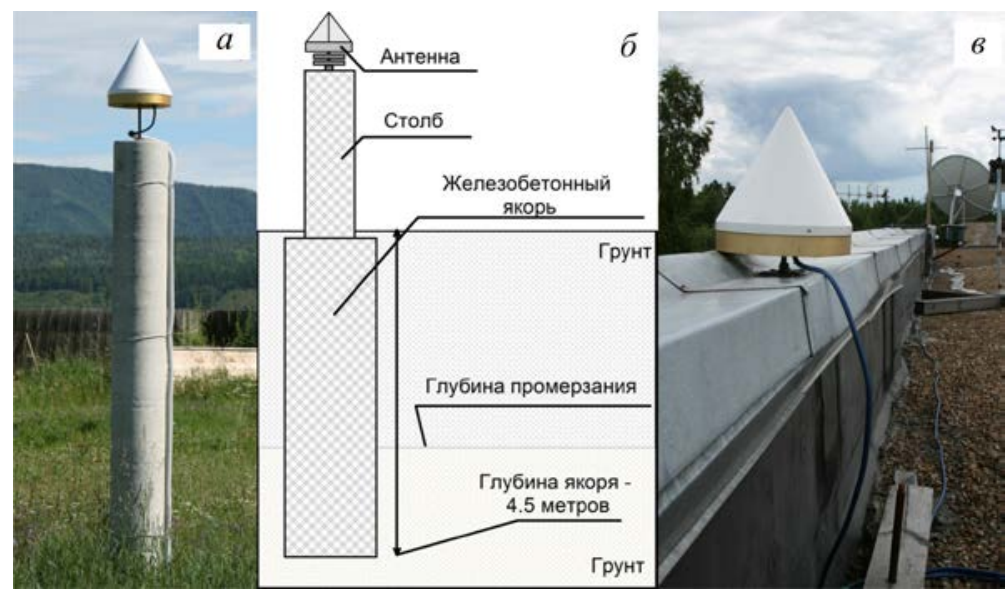

Puc. 4. Внешний вид железобетонного репера (a) и схема установки на осадочных/наносных породах на станции TORY (б); антенна на крыше устоявшегося капитального строения ORDA (в)

Таблица 2

Характеристики станций SibNet в Прибайкалье

\begin{tabular}{|l|l|l|l|l|}
\hline Станция & Тип станции & Tип приемника & \multicolumn{1}{|c|}{$\begin{array}{c}\text { Тип репера (фундамента) } \\
\text { для антенны }\end{array}$} & $\begin{array}{c}\text { Дата начала } \\
\text { регулярных наблюдений }\end{array}$ \\
\hline TORY & Постоянная & SigmaQ-G3D & Железобетонный якорь & 20.03 .2012 \\
\hline LIST & Постоянная & Delta-G3T & Коренные породы & 15.06 .2012 \\
\hline ORDA & Постоянная & Delta-G3T & Капитальное здание & 14.06 .2011 \\
\hline UZUR & Постоянная & Delta-G3T & Коренные породы & 21.03 .2013 \\
\hline MOND & Постоянная & Delta-G3T & Коренные породы & 11.09 .2013 \\
\hline ISTP & Постоянная & Delta-G3T & Капитальное здание & 01.04 .2012 \\
\hline SARM & Постоянная & Delta-G3T & Крыша деревянного здания & 02.12 .2012 \\
\hline MKSM & Временная & Delta-G3T & Крыша деревянного здания & 27.04 .2014 \\
\hline ZAKT & Временная & Delta-G3T & Деревянный столб & нерегулярные \\
\hline ZMUR & Временная & Delta-G3T & Деревянный столб & нерегулярные \\
\hline BDRY & Временная & Delta-G3T & Крыша капитального здания & нерегулярные \\
\hline PATR & Временная & Delta-G3T & Крыша деревянного здания & нерегулярные \\
\hline BBSH & Временная & Delta-G3T & Крыша деревянного здания & нерегулярные \\
\hline SHCH & Временная & Delta-G3T & Крыша деревянного здания & нерегулярные \\
\hline
\end{tabular}


под управлением операционной системы (OC) Linux в ИСЗФ СО РАН разработана программа, предназначенная для управления и сбора данных с двухчастотного ГНСС-приемника Javad Delta-G3T через интерфейсы USB и RS-232 в OC Linux [Перевалов, Перевалова, 2016]. Программа реализована в виде консольного приложения OC Linux и может выполняться как в интерактивном, так и пакетном режимах. Программа обеспечивает установку параметров измерений, получение данных измерений с заданной частотой дискретизации, контроль целостности полученных данных, исправление последствий технических сбоев в данных, запись данных в файлы на жесткий диск компьютера в формате JPS (стандартный формат файлов приемников JAVAD GNSS [GREIS, 2010]).

Используемые в SibNet приемники не обладают встроенной памятью для записи измерений, поэтому они подключены к управляющему компьютеру (рис. 2) для организации временного хранения и последующей передачи в центр хранения данных, расположенный в ИСЗФ СО РАН. В стандартном режиме приемники SibNet ведут запись параметров сигнала с частотой 1 Гц. Для проведения отдельных экспериментов применяются режимы с увеличением частоты записи до 50 Гц.

\section{ПОКРЫТИЕ РАДИОТРАССАМИ ГНСС ЮЖНОГО ПРИБАЙКАЛЬЯ}

Каждый приемник ГНСС в любой момент времени принимает сигналы не менее 8 спутников GPS и не менее 7 спутников ГЛОНАСС. В практике ионосферных исследований видимое перемещение спутников ГНСС принято отображать с помощью перемещения ионосферных точек. Ионосферной точкой называют место пересечения радиолуча приемник - спутник ГНСС с условной тонкой сферой, расположенной на высоте $h_{\max }$ главного максимума электронной концентрации в ионосфере. Данная высота выбрана в силу того, что именно область вблизи главного максимума ионизации вносит максимальный вклад в ПЭС. В общем случае эта высота имеет сезонную, суточную и другие зависимости и может меняться от 200 до 400 км. Для каждого спутника ионосферная точка может быть удалена от положения приемника на расстояние до $15^{\circ}$ по долготе и широте (рис. 5).

Период обращения спутников GPS (11 ч 58 мин) подобран таким образом, что каждый день спутник пролетает по одной и той же траектории относительно неподвижного наземного наблюдателя. Период обращения спутников ГЛОНАСС (11 ч 15 мин) подобран таким образом, что положение траектории спутника ГЛОНАСС за 1 сут смещается относительно Земли на $22.5^{\circ}$, т. е. спутник повторяет свою траекторию относительно наземного наблюдателя через 8 сут.

Перемещение спутников ГНСС по куполу неба, с одной стороны, создает определенные сложности: 1) в вариациях ПЭС присутствует тренд, связанный с неодинаковой эффективной толщиной ионосферы при разных углах места спутников (рис. 6, a); 2) существует дополнительная сложность определения

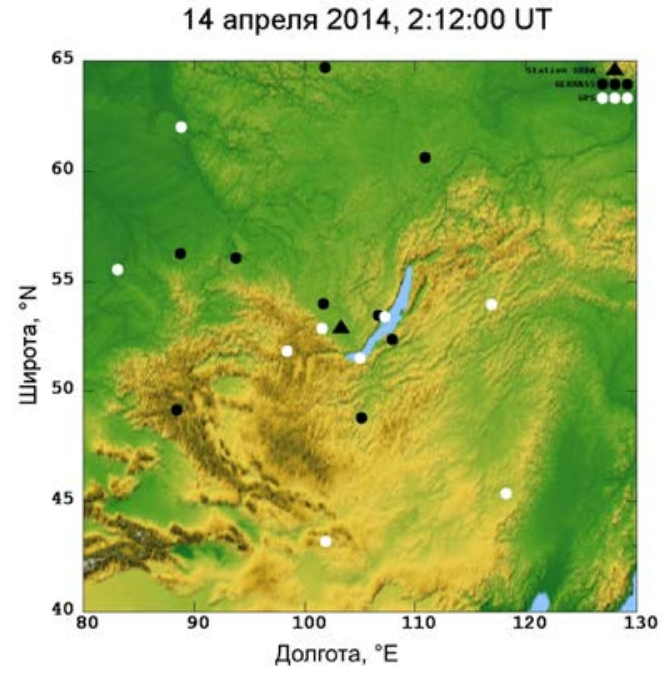

Puc. 5. Положение ионосферных точек спутников ГЛОНАСС (черные точки) и GPS (белые точки) для приемника ORDA (треугольник) в выделенный момент времени

скоростей и направлений перемещения ионосферных возмущений. С другой стороны, движение спутников ГНСС позволяет за сутки просканировать практически весь небосвод с помощью одного приемника. Так, на рис. 7 показаны положения ионосферных точек для спутников ГЛОНАСС и GPS, полученные за 1 сут по данным станции MOND. Таким образом, с помощью одной станции в средних широтах сканирование ионосферы происходит для области порядка $30^{\circ}$ по широте и более $40^{\circ}$ по долготе.

Можно видеть (рис. 7), что в северном направлении существует определенная «слепая» зона, т. е. некоторая часть небосвода, где спутники ГНСС не наблюдаются. Связано это с наклонением орбит спутников ГНСС. Для GPS наклонение орбит отно-

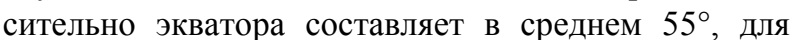
ГЛОНАСС - $64.8^{\circ}$ (реальные наклонения орбит могут значительно отличаться от расчетных, например, для системы GPS наклонения меняются от 51 до $57^{\circ}$ ). Как видно на рис. 7 , слепая зона для ГЛОНАCC значительно меньше. Поэтому с точки зрения покрытия территории для исследования ионосферы на средних и высоких широтах система ГЛОНАСС более предпочтительна, чем GPS.

\section{ПЕРВЫЕ РЕЗУЛЬТАТЫ РЕГИСТРАЦИИ ИОНОСФЕРНЫХ ЭФФЕКТОВ ДУ ТГК «ПРОГРЕСС»}

Сеть SibNet наряду с другими инструментами ИСЗФ СО РАН использовалась для регистрации ионосферных эффектов работы ДУ ТГК «Прогресс». Для увеличения плотности сети наблюдательных пунктов ГНСС дополнительно были развернуты временные приемные станции (рис. 1). Поскольку долговременные ряды данных этих станций не используются в геодинамических измерениях, требования к установке антенн могли быть не такими жесткими, как для постоянных пунктов. В частности, 


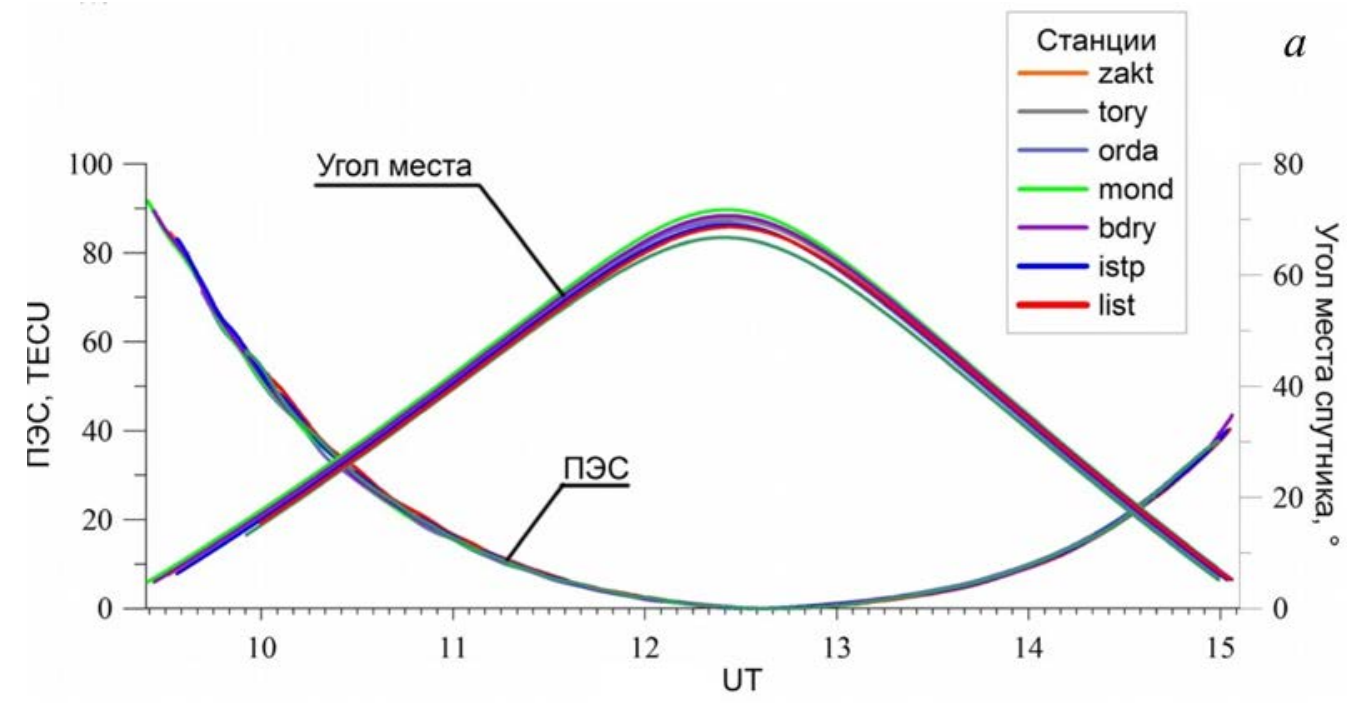

Спутник PRN 08 GPS, 16 апреля 2014 г.

$\sigma$

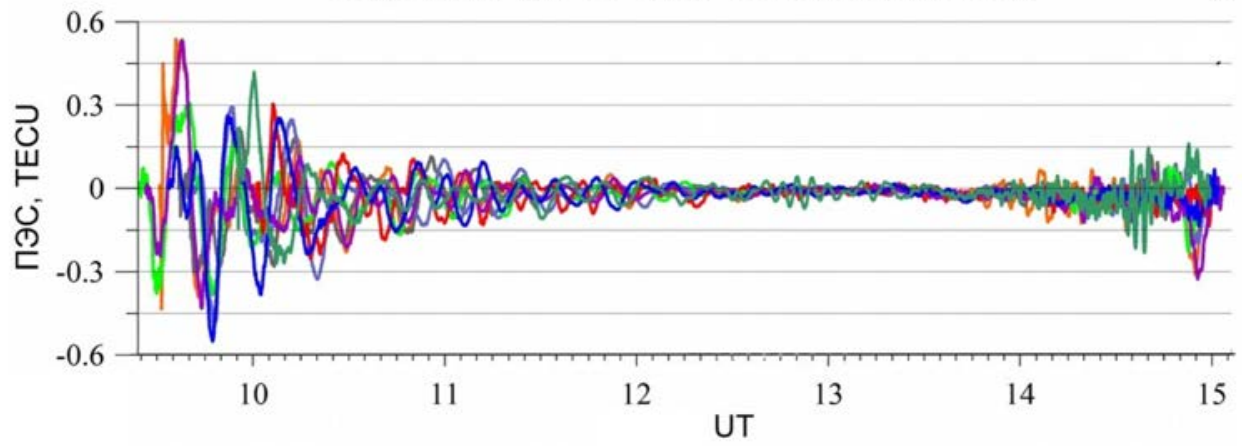

Pис. 6. Данные вариаций ПЭС, полученные по сигналам одного спутника на разнесенных станциях: неотфильтрованные данные с наличием временного тренда, связанного с углом места спутника $(a)$; те же данные, отфильтрованные скользящим средним с временным окном 0.5-10 мин (б)

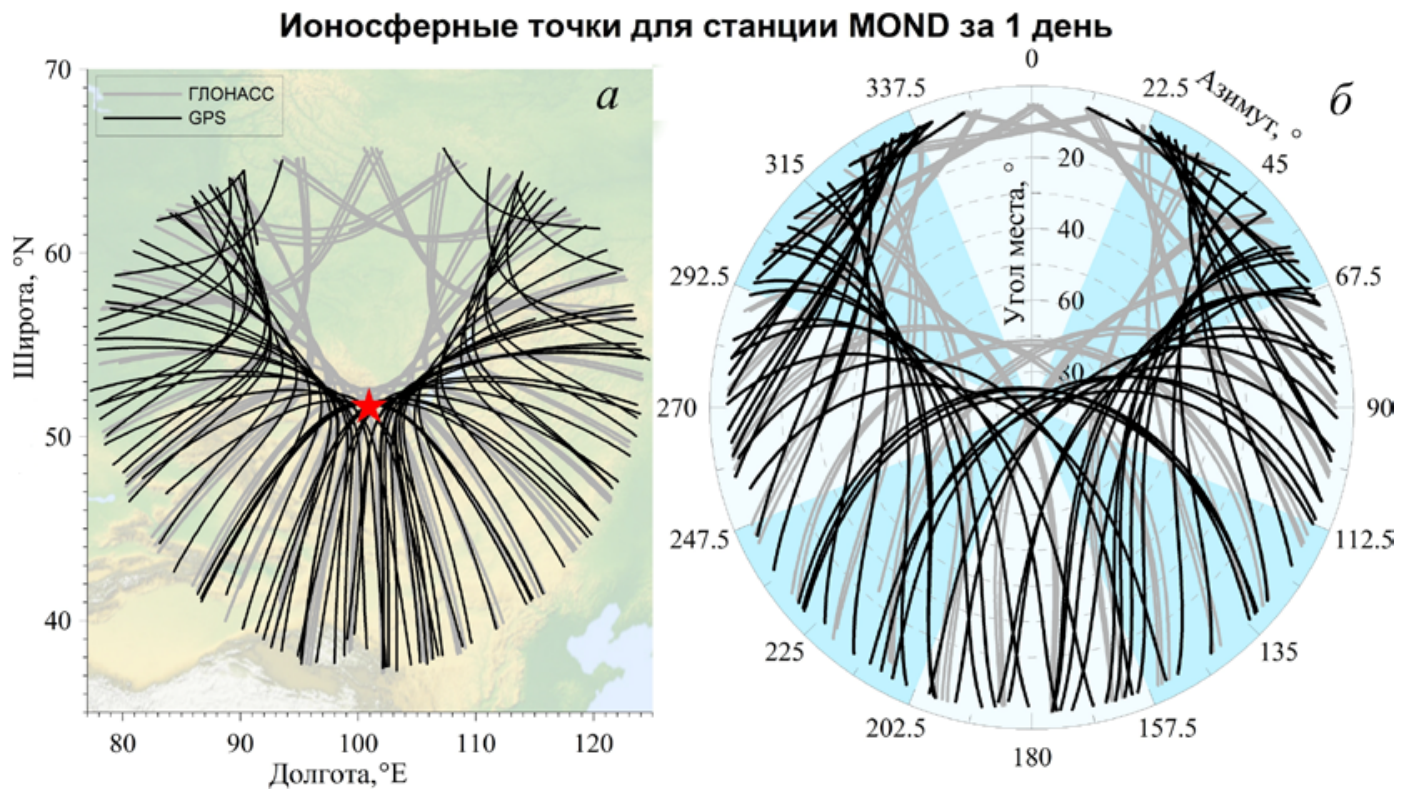

Puc. 7. Ионосферные точки для станции MOND за 1 сутки в координатах долгота-широта (a) и угол места - азимут спутника ГНСС (б) по всем доступным спутникам. Серыми линиями показаны ионосферные точки для ГЛОНАСС, черными — для GPS

для ионосферных измерений во время активных КЭ 2014-2016 гг. временные антенны устанавливались на деревянных столбах, крышах зданий и т. п. (рис. 8).
Расчет вариаций ПЭС по данным ГЛОНАCC/GPS проводился по единой стандартной методике на основе двухчастотных фазовых измерений прием- 
ника ГНСС [Hofmann-Wellenhof et al., 1992]. При высокой точности фазовых измерений в ГНСС погрешность определения ПЭС не превышает 0.01 TECU [Hofmann-Wellenhof et al., 1992], что позволяет детектировать достаточно слабые возмущения. Для расчета ПЭС использовались данные как GPS, так и ГЛОНАСС. Исходные ряды вариаций ПЭС (рис. 6, a) были отфильтрованы методом скользящего среднего [Афраймович, Перевалова, 2006] в диапазоне периодов 0.5-10 мин (рис. 6, б). Поскольку было известно, что высота пролета ТГК «Прогресс» составляла порядка 400 км [Khakhinov et al., 2011, 2012; Хахинов и др., 2012, 2013], мы рассчитывали координаты ионосферных точек для этой высоты $\left(h_{\max }=400\right.$ км).

Во время экспериментов по обнаружению ионосферных эффектов активного воздействия струи ДУ ТГК «Прогресс» использовался метод картирования ионосферных возмущений [Perevalova et al., 2008; Tsugawa et al., 2011; Куницын и др., 2011; Перевалова и др., 2012; Afraimovich et al., 2013; Astafyeva et al., 2013]. Суть метода заключается в том, что для каждого текущего момента времени на карту наносится положение ионосферных точек для всех лучей приемник-спутник, при этом цвет точек соответствует текущему значению амплитуды вариаций ПЭС на данном луче, которая является индикатором возмущенности ионосферы. Метод позволяет визуально проследить пространственно-временную динамику возмущений ПЭС. При исследовании ПИВ построение последовательности таких карт для соседних моментов времени является очень удобным инструментом для визуальной оценки параметров ПИВ, таких как интенсивность, скорость, направление.

Положение ионосферных точек на карте дает наглядное представление о геометрии эксперимента 16 апреля 2014 г. (рис. 9). Можно видеть, что наблюдаются как отрицательные, так и положительные возмущения ПЭС. Локальный характер воздействия ДУ на ионосферу требовал тщательного анализа данных, полученных на радиолучах, проходивших вблизи области воздействия и пересекавших эту область. Для такого анализа было проведено картирование области воздействия с нанесением ионо-

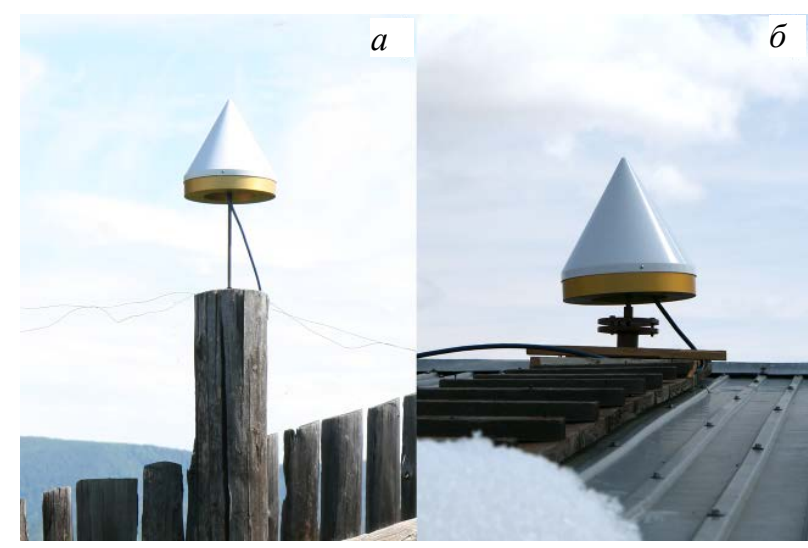

Puc. 8. Антенны временных пунктов наблюдений, установленные на деревянном столбе забора (a) и на крыше здания (б) сферных точек для спутника PRN 08 GPS (рис. 10). Ионосферные точки для этого спутника и разных станций пересекали область воздействия через 9 мин (рис. 10, a) и через 22 мин (рис. 10, б). На рис. 11 показаны вариации ПЭС для данного спутника на различных станциях ГНСС. Момент пересечения ионосферной точкой луча PRN08-LIST области воздействия (рис. 10, б) соответствует моменту максимального уменьшения ПЭС в данных станции LIST для спутника PRN 08 GPS (рис. 11, момент обозначен вертикальной красной линией). Этот факт позволяет предположить наличие связи между активным воздействием и наблюдаемым минимумом несмотря на то, что в данных других станций есть сравнимые по интенсивности вариации ПЭС. Амплитуда наблюдаемого возмущения составляет 0.07 TECU, что превышает погрешность определения ПЭС (0.01 TECU) и уровень фоновых вариаций на близких углах места спутника ( 0.02 TECU). Значительных геомагнитных возмущений 16 апреля 2014 г. не регистрировалось: индекс $K_{\mathrm{p}}$ не превышал 1.3 за последние 6 ч перед экспериментом. Принимая во внимание пространственно-временную локализацию минимума ПЭС и локальность воздействия, можно сделать вывод о том, что именно воздействие струи ДУ вызывает падение электронной концентрации.

Однако такие уменьшения вариаций ПЭС наблюдаются не всегда. При пересечении другой ионосферной точкой (луч PRN08-ISTP) области воздействия (рис. 11), сколько-нибудь значительного уменьшения ПЭС на луче не зарегистрировано. Связано это, по-видимому, с большим временным отрезком, прошедшим с момента включения ДУ до момента прохождения ионосферной точки через область воздействия (рис. 11, вертикальная синяя линия).

Указанные случаи пересечения ионосферными точками области воздействия произошли при очень

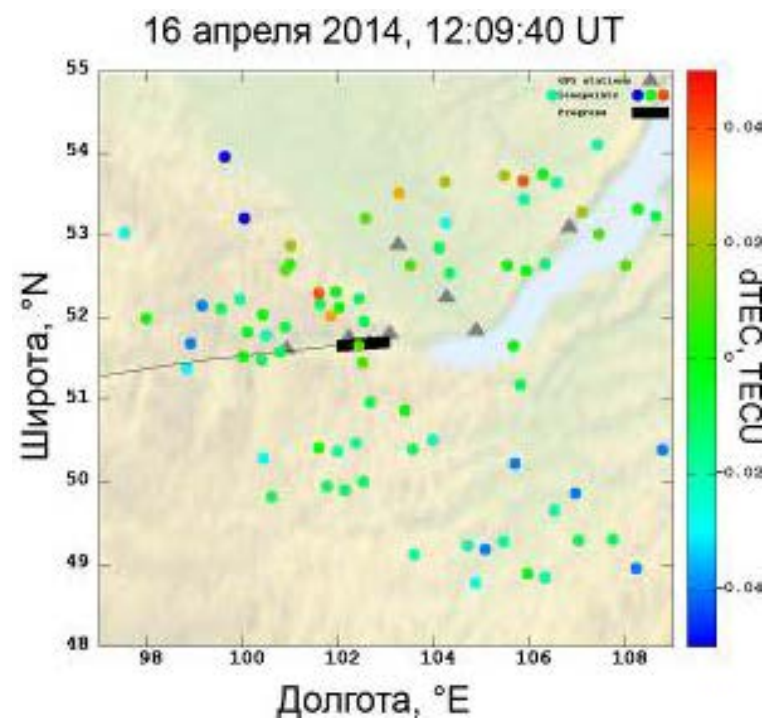

Puc. 9. Ионосферные точки для сети SibNet во время эксперимента 16 апреля 2014 г. Цветом точки показано мгновенное значение вариаций ПЭС на соответствующем луче спутник-приемник. Треугольники - станции ГНСС, сплошная линия - траектория ТГК «Прогресс», утолщенный участок траектории - полет ТГК с работающей ДУ 

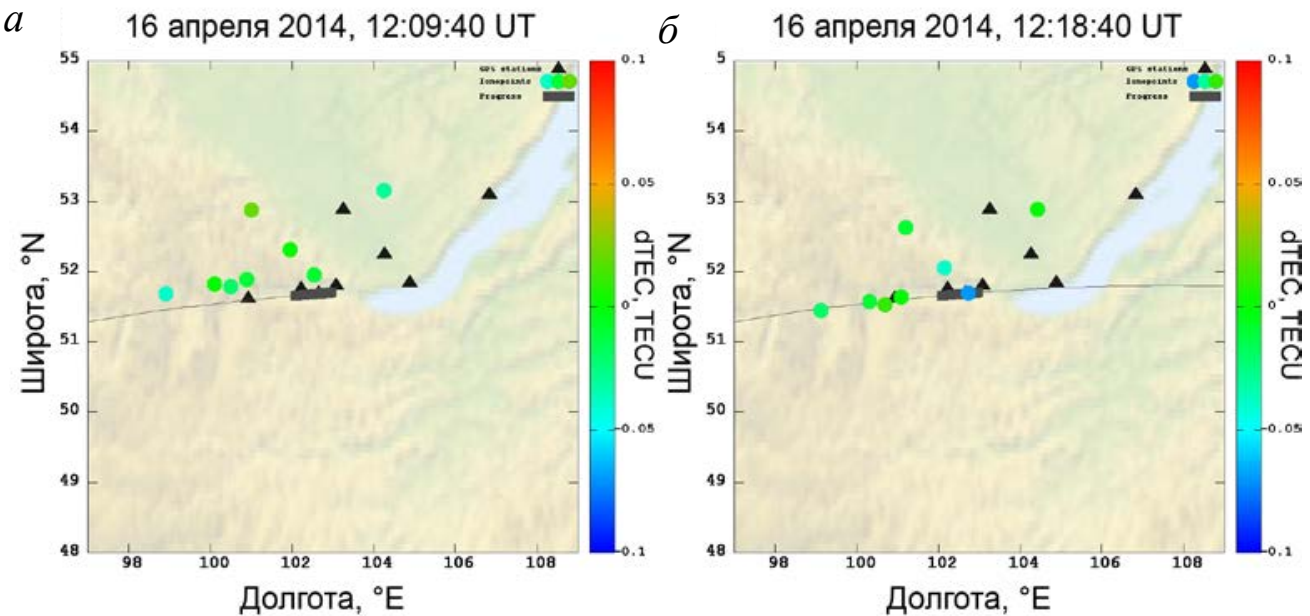

Puc. 10. Ионосферные точки для спутника PRN 08 GPS во время эксперимента 16 апреля 2014 г. Обозначения те же, что на рис. 9

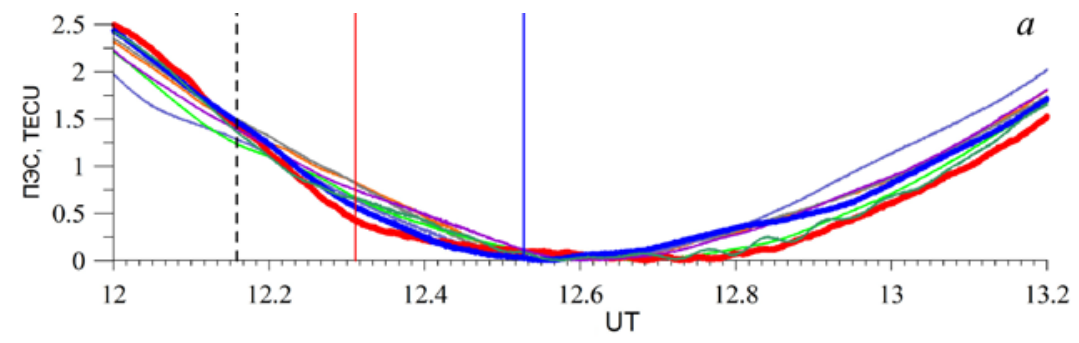

Спутник PRN 08 GPS, 16 апреля 2014 r.

$\sigma$

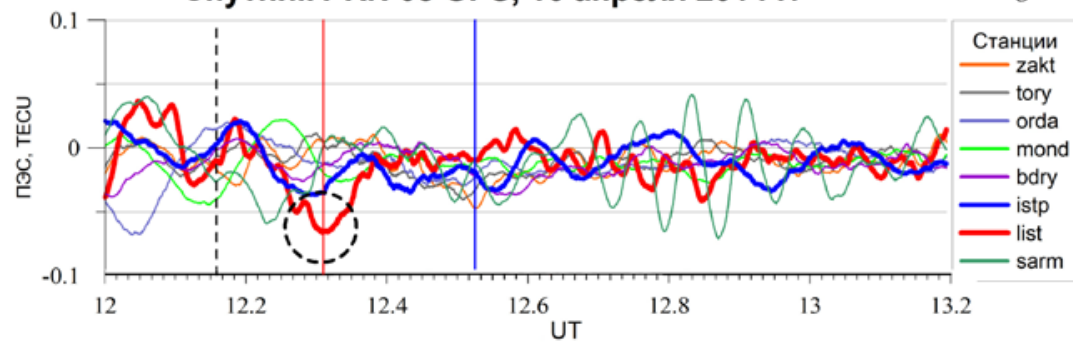

Puc. 11. Данные вариаций ПЭС, полученные по сигналам спутникам PRN 08 GPS на разнесенных станциях: неотфильтрованные данные $(a)$; те же данные, отфильтрованные скользящим средним с временным окном 2-10 мин (б). Вертикальной штриховой линией отмечен момент включения ДУ

благоприятной геометрии измерений: угол места спутника PRN 08 GPS был максимальным для текущего ряда данных (рис. 6, a). Это позволило избежать регистрации значительных по амплитуде вариаций ПЭС, которые наблюдались за два часа до этого и спустя два часа (рис. $6, a$ ). Такая геометрия эксперимента была крайне удачной для обнаружения отклика на работу ДУ ТГК «Прогресс».

Подробный анализ параметров отклик ионосферы на воздействие ДУ ТГК во всех проводившихся активных экспериментах приведен в статье [Ишин и др., 2017].

\section{ЗАКЛЮЧЕНИЕ}

В результате развертывания сети SibNet двухчастотных ГНСС-приемников в Южном Прибайкалье появился эффективный инструмент мониторинга состояния ионосферы. Благодаря установке антенн на специально оборудованные постаменты, данные этой сети дополнительно могут быть использованы для изучения движения литосферных плит, что также является актуальной задачей в сейсмически активной Байкальской рифтовой системе.

SibNet функционирует в постоянном режиме, что позволяет не только проводить заранее спланированные и поставленные эксперименты, но и исследовать геофизические отклики на сложнопредсказуемые явления, такие как землетрясения, падение метеоров, взрывы болидов в атмосфере и т. п.

Метод картирования ионосферных возмущений, неоднократно использовавшийся для обнаружения ПИВ [Perevalova et al., 2008; Tsugawa et al., 2011; Куницын и др., 2011; Перевалова и др., 2012; Afraimovich et al., 2013; Astafyeva et al., 2013; Ясюкевич и др., 2015; Захаров и др., 2016], показал свою эффективность также и при обнаружении локализованных возмущений. Были обнаружены относительно слабые и высотно-локализованные возмущения, вызванных воздействием двигательной установки космического корабля «Прогресс» в эксперименте 16 
апреля 2014 г. С помощью метода картирования показано, что эти возмущения можно однозначно связать с воздействием двигателя ТГК «Прогресс».

Таким образом, развертывание SibNet значительно расширило возможности исследования локальных геофизических событий, а также дополнило мировую сеть станций приемников ГНСС. Первые результаты, полученные с помощью SibNet, показывают эффективность применения таких сетей, в том числе и при проведении активных экспериментов в ионосфере Земли.

Работа выполнена в рамках проекта № AАAАА16-116012210460-0 «Исследование системы литосфера-атмосфера-ионосфера в экстремальных условиях» программы Президиума РАН № 15 при поддержке гранта РФФИ № 16-35-00027_мол_а «Исследование отклика ионосферы на одновременное воздействие различных источников в нейтральной атмосфере» 2016-2017 гг. Экспериментальные данные получены с использованием оборудования Центра коллективного пользования «Ангара» ИСЗФ СО РАН.

\section{СПИСОК ЛИТЕРАТУРЫ}

Афраймович Э.Л., Перевалова Н.П. GPS-мониторинг верхней атмосферы Земли. Иркутск: Изд-во ГУ НЦ РВХ ВСНЦ СО РАМН. 2006. С. 480.

Белецкий А.Б., Михалев А.В., Хахинов В.В., Лебедев В.П. Оптическое проявление работы бортовых двигателей низкоорбитальных космических аппаратов // Солнечноземная физика. 2016. Т. 2, № 4. С. 85-91. DOI: $10.12737 /$ 21169.

Борисов Б.С., Габдуллин Ф.Ф., Гаркуша В.И., Корсун А.Г., Куршаков М.Ю., Страшинский В.А., Твердохлебова Е.М., Хахинов В.В. Радиофизические характеристики плазменного окружения низкоорбитальных КА по данным космических экспериментов // Нелинейный мир. 2012. T. 10, № 10. C. 700-709.

Еселевич М.В., Хахинов В.В., Клунко Е.В. Параметры оптических сигналов на телескопе АЗЕ-33ИК, зарегистрированных в активном космическом эксперименте «РадарПрогресс» // Солнечно-земная физика. 2016. Т. 2, № 3 . C. 24-32. DOI: 10.12737/20494.

Жеребцов Г.А., Перевалова Н.П. Реакция ионосферы на запуск ракеты с космодрома Восточный // Доклады академии наук. 2016. Т. 471, № 5. С. 586-589.

Захаров В.И., Ясюкевич Ю.В., Титова М.А. Влияние магнитных бурь и суббурь на свои навигационной системы GPS в высоких широтах // Космические иссл. 2016. Т. 54, № 1. C. 23-33.

Институт солнечно-земной физики: создание и развитие / отв. ред. Жеребцов Г.А. Новосибирск: Изд-во СО PAH, 2015. С. 610.

Ишин А.Б., Перевалова Н.П., Воейков С.В. Комплексный анализ реакции ионосферы на работу двигательных установок ТГК «Прогресс» по данным ГНСС-приемников в Байкальском регионе // Солнечно-земная физика. 2017. T. 3, № 4. C. 93-103. DOI: 10.12737/iszf-34201709.

Клунко Е.В., Еселевич М.В., Тергоев В.И. Наблюдения ТГК «Прогресс» на оптическом телескопе АЗЕ-33ИК // Солнечно-земная физика. 2016. Т. 2, № 3. С. 17-23. DOI: 10/12737/20492.

Куницын В.Е., Нестеров И.А., Шалимов С.Л. Мегаземлетрясение в Японии 11 марта 2011 г.: регистрация ионосферных возмущений по данным GPS // Письма в ЖЭТФ. 2011. Т. 94, № 8. С. 657-661.

Лебедев В.П., Хахинов В.В., Кушнарев Д.С. и др. Радиофизические эффекты работы двигателя космического аппарата // XXIV Всероссийская научная конференция, посвященная 100-летию со дня рождения проф. В.М. Полякова «Распространение радиоволн» (РРВ-24, Иркутск, 29 июня - 5 июля 2014): Труды конференции. 2014. Т. 1. C. 60-66.

Липко Ю.В., Пашинин А.Ю., Рахматулин Р.А., Хахинов В.В. Эффекты в магнитном поле земли от работы двигателей космического корабля // Солнечно-земная физика. 2016. Т. 2, № 3. С. 33-40. DOI: 10.12737/19634.

Перевалова Н.П., Воейков С.В., Ясюкевич Ю.В., Ишин А.Б., Воейкова Е.С., Саньков В.А. Исследование ионосферных возмущений, вызванных землетрясением в Японии 11 марта 2011 г., по данным сети GEONET // Coвременные проблемы зондирования Земли из космоса. 2012. T. 9, № 3. С. 172-180.

Перевалов А.А., Перевалова Н.П. Управление и сбор данных с двухчастотного ГНСС-приемника Javad Delta через интерфейсы USB и RS-232 в интерактивном и пакетном режимах в операционной системе Linux // Свидетельство о государственной регистрации программы для ЭВМ № 2016613942. 12.04.2016.

Сейсмоионосферные и сейсмоэлектромагнитные процессы в Байкальской рифтовой зоне / отв. ред. Жеребцов Г.А. Новосибирск: Изд-во СО РАН, 2012. 304 с. (Интеграционные проекты СО РАН. Вып. 35).

Хахинов В.В., Потехин А.П., Лебедев В.П., Медведев А.В., Кушнарев Д.С., Шпынев Б.Г., Заруднев В.Е., Алсаткин С.С., Ратовский К.Г., Подлесный А.В., Брынько И.Г. Радиофизические методы диагностики ионосферных возмущений, генерируемые бортовыми двигателями ТГК «Прогресс»: алгоритмы, инструменты и результаты // Журнал радиоэлектроники. 2010. С. 553-569.

Хахинов В.В., Потехин А.П., Лебедев В.П., Алсаткин С.С., Ратовский К.Г., Кушнарев Д.С., Твердохлебова Е.М., Куршаков М.Ю., Манжелей А.И., Тимофеева Н.И. Результаты дистанционного зондирования ионосферных возмущений в активных космических экспериментах «Радар-Прогресс» // Современные проблемы дистанционного зондирования Земли из космоса. 2012. Т. 9, № 3. С. 199-206.

Хахинов В.В., Потехин А.П., Лебедев В.П., Кушнарев Д.С., Алсаткин С.С. Некоторые результаты активных космических экспериментов «Плазма-Прогресс» и «Радар-Прогресс» // Вестник Сибирского государственного аэрокосмического университета им. академика М.Ф. Решетнева. 2013. Спец. вып. Т. 5, № 51. С. 160-162.

Шпынев Б.Г., Алсаткин С.С., Хахинов В.В., Лебедев В.П. Исследование реакции ионосферы на продукты горения топлива при работе двигателей транспортных грузовых кораблей серии «Прогресс» по данным Иркутского радара некогерентного рассеяния // Солнечно-земная физика. 2017. Т. 3, № 1. С. 88-96. DOI: 10.12737/22812.

Ясюкевич Ю.В., Захаров В.И., Куницын В.Е., Воейков С.В. Отклик ионосферы на землетрясение в Японии 11 марта 2011 г. по данным различных GPS-методик // Геомагнетизм и аэрономия. 2015. Т. 55, № 1. С. 113.

Afraimovich E.L. GPS global detection of the ionospheric response to solar flares // Radio Sci. 2000. V. 35, N 6. P. 14171424.

Afraimovich E.L., Astafyeva E.I., Demyanov V.V., Edemsky I.K., Gavrilyuk N.S., Ishin A.B., Kosogorov E.A., Leonovich L.A., Lesyuta O.S., Palamarchuk K.S., Perevalova N.P., Polyakova A.S., Smolkov G.Ya., Voeykov S.V., Yasyukevich Yu.V., Zhivetiev I.V. A review of GPS/GLONASS studies of the ionospheric response to natural and anthropogenic processes and phenomena // J. Space Weather Space Climate. 2013. N 3. P. A27_p1-A27_P19. DOI: 10.1051/ swsc/2013049 
Afraimovich E.L., Voeykov S.V., Perevalova N.P. et al. Ionospheric effects of the March 29, 2006, solar eclipse over Kazakhstan // Geomagnetism and Aeronomy. 2007. V. 47, N 4. P. 461469.

Astafyeva E., Rolland L., Lognonne P., Khelfi K., Yahagi T. Parameters of seismic source as deduced from $1 \mathrm{~Hz}$ ionospheric GPS data: Case study of the 2011 Tohoku-Oki event // J. Geophys. Res.: Space Phys. 2013. V. 118. P. 59425950. DOI: 10.1002/jgra.50556

Demyanov V.V., Afraimovich E.L., Jin S. An evaluation of potential solar radio emission power threat on GPS and GLONASS performance // GPS Solutions. 2012. V. 16, N 4. P. 411-424.

Demyanov V.V., Yasyukevich Yu.V. Deterioration in the accuracy of GPS system positioning due to the effect of ionospheric bubbles // Geomagnetism and Aeronomy. 2011. V. 51, N 7. P. 1010-1013.

Ding F., Wan W., Mao T. et al. Ionospheric response to the shock and acoustic waves excited by the launch of the Shenzhou-10 spacecraft // Geophys. Res. Lett. 2014. V. 41. P. 3351-3358.

GREIS: GNSS Receiver External Interface Specification. Version 3.2.0. Javad GNSS. 2010. URL: www.javad.com/jgnss/ support/manuals.html

Jiao Y., Morton Y.T., Taylor S., Pelgrum W. Characterization of high-latitude ionospheric scintillation of GPS signals // Radio Sci. 2013. V. 48, iss. 6. P. 698-708.

Hofmann-Wellenhof B., Lichtenegger H., Collins J. Global Positioning System: Theory and Practice. New York. Springer-Verlag Wien, 1992. P. 327.

Khakhinov V., Potekhin A., Shpynev B., Alsatkin S., Ratovsky K., Lebedev V., Kushnarev D. Results of complex radiosounding of ionospheric disturbances generated by the transport spacecraft Progress onboard thrusters // $201130^{\text {th }}$ URSI General Assembly and Scientific Symposium URSIGASS 2011. 2011. P. 6051169.

Khakhinov V.V., Shpynev B.G., Lebedev V.P., Kushnarev D.S., Alsatkin S.S., Khabituev D.S. Radiosounding of ionospheric disturbances generated by exhaust streams of the transport spacecraft Progress engines // Proc. PIERS-2012. (Progress in Electromagnetics Research Symposium). Moscow. 2012. P. 1168-1171.

Lejeune S, Wautelet G, Warnant R Ionospheric effects on relative positioning within a dense GPS network // GPS Solutions. 2012. V. 16, N 1. P. 105-116.

Liu J.Y., Lin C.H. Ionospheric solar flare effects monitored by the ground based GPS receivers: Theory and observation // J. Geophys. Res. 2004. V. 109. A01307.

Perevalova N.P., Afraimovich E.L., Voeykov S.V., Zhivetiev I.V. Parameters of large scale TEC disturbances during strong magnetic storm on October 29, 2003 // J. Geophys. Res. 2008. V. 113. A00A13. DOI: 10.1029/2008JA013137

Prikryl P., Jayachandran P.T., Mushini S.C., Pokhotelov D., MacDougall J.W., Donovan E., Spanswick E., St.-Maurice J.-P. GPS TEC, scintillation and cycle slips observed at high latitudes during solar minimum // Ann. Geophys. 2010. V. 28. P. 1307-1316.

Shimeis A., Borries C., Amory-Mazaudier C., Fleury R., Mahrous A.M., Hassan A.F., Nawar S. TEC variations along an East Euro-African chain during $5^{\text {th }}$ April 2010 geomagnetic storm // Adv. Space Res. 2015. N 55. P. 2239-2247.

Spogli L., Alfonsi L., Cilliers P.J., Correia E., Franceschi G., Mitchell C.N., Romano V., Kinrade J., Cabrera M.A. GPS scintillations and total electron content climatology in the southern low, middle and high latitude regions // Ann. Geophys. 2013. V. 56, N 2. R0220.

Tsugawa T., Saito A., Otsuka Y. et al. Ionospheric disturbances detected by GPS total electron content observation after the 2011 Tohoku Earthquake // Earth, Planets and Space. 2011. V. 63. N 7. P. 875-879.

Zherebtsov G.A., Perevalova N.P. Ionospheric response to a rocket launch from the Vostochnyi cosmodrome // Doklady Earth Sci. 2016. V. 471, part 2. P. 1280-1283.

\section{REFERENCES}

Afraimovich E.L. GPS global detection of the ionospheric response to solar flares. Radio Sci. 2000, vol. 35, no. 6, pp. 14171424.

Afraimovich E.L., Astafyeva E.I., Demyanov V.V., Edemsky I.K., Gavrilyuk N.S., Ishin A.B., Kosogorov E.A., Leonovich L.A., Lesyuta O.S., Palamarchuk K.S., Perevalova N.P., Polyakova A.S., Smolkov G.Ya., Voeykov S.V., Yasyukevich Yu.V., Zhivetiev I.V. A review of GPS/GLONASS studies of the ionospheric response to natural and anthropogenic processes and phenomena. J. Space Weather Space Climate. 2013, no. 3, pp. A27_p1-A27_p19. DOI: 10.1051/swsc/2013049.

Afraimovich E.L., Perevalova N.P. GPS-monitoring verhnei atmosfery Zemli [GPS-monitoring of the Earth's upper atmosphere]. Irkutsk, 2006, 480 p. (In Russian).

Afraimovich E.L., Voeykov S.V., Perevalova N.P., Vodyannikov V.V., Gordienko G.I., Litvinov Yu.G., Yakovets A.F. Ionospheric effects of the March 29, 2006, solar eclipse over Kazakhstan. Geomagnetism and Aeronomy. 2007, vol. 47, no. 4, pp. 461-469.

Astafyeva E., Rolland L., Lognonne P., Khelfi K., Yahagi T. Parameters of seismic source as deduced from $1 \mathrm{~Hz}$ ionospheric GPS data: Case study of the 2011 Tohoku-Oki event. J. Geophys. Res. Space Phys. 2013, vol. 118, pp. 5942-5950. DOI: 10.1002/jgra.50556.

Beletsky A.B., Mikhalev A.V., Khakhinov V.V., Lebedev V.P. Optical manifestation of functioning onboard engines of low-orbit spacecraft. Solar-Terr. Phys. 2016, vol. 2, no. 4, pp. 85-91.

Borisov B.S., Gabdullin F.F., Garkusha V.I., Korsun A.G., Kurshakov M.Yu., Strashinsky V.A., Tverdokhlebova E.M., Khakhinov V.V. Radiophysical characteristics of low-orbit spacecraft plasma environment revealed by space experiments. Nelineinyi mir [J. Nonlinear World]. 2012, vol. 10, no. 10, pp. 700-709. (In Russian).

Demyanov V.V., Afraimovich E.L., Jin S. An evaluation of potential solar radio emission power threat on GPS and GLONASS performance. GPS Solutions. 2012, vol. 16, no. 4, pp. 411-424.

Demyanov V.V., Yasyukevich Yu.V. Deterioration in the accuracy of GPS system positioning due to the effect of ionospheric bubbles. Geomagnetism and Aeronomy. 2011, vol. 51, no. 7, pp. 1010-1013.

Ding F., Wan W., Mao T., Wang M., Ning B., Zhao B., Xiong $\mathrm{B}$. Ionospheric response to the shock and acoustic waves excited by the launch of the Shenzhou-10 spacecraft. Geophys. Res. Let., 2014, vol. 41, pp. 3351-3358.

Eselevich M.V., Khakhinov V.V., Klunko E.V. Parameters of optical signals registered with the AZT-33IK telescope in active radar-progress space experiment. Solar-Terr. Phys. 2016, vol. 2, no. 3, pp. 32-43.

GREIS: GNSS Receiver External Interface Specification. Version 3.2.0. Javad GNSS. 2010. Available at: www.javad. com/jgnss/support/manuals.html (accessed 12 May 2017).

Hofmann-Wellenhof B., Lichtenegger H., Collins J. Global Positioning System: Theory and Practice. New York. Springer-Verlag Wien, 1992, p. 327.

Institut solnechno-zemnoi fiziki: sozdanie i razvitie. Ed. Zherebtsov G.A. [Institute of Solar-Terrestrial Physics: Foundation and Development. Ed. Zherebtsov G.A.]. Novosibirsk: SB RAS Publ., 2015, 610 p.

Ishin A.B., Perevalova N.P., Voeykov S.V., Khakhinov V.V. Complex analysis of the ionospheric response to operation of 
Progress cargo spacecraft according to the data of GNSS receivers in Baikal region. Solar-Terr. Phys. 2017, vol. 3, no. 4, pp. 93-103. (In Russian).

Jiao Y., Morton Y.T., Taylor S., Pelgrum W. Characterization of high-latitude ionospheric scintillation of GPS signals, Radio Sci. 2013, vol. 48, iss. 6, pp. 698-708.

Khakhinov V.V., Potekhin A.P., Lebedev V.P., Alsatkin S.S., Ratovsky K.G, Kushnarev D.S., Tverdokhlebova E.M., Kurshakov M.Yu., Manzheley A.I., Timofeeva N.I. Results of remote sounding of ionospheric disturbances during active experiments Radar-Progress. Sovremennye problemy distantsionnogo zondirovaniya Zemli iz kosmosa [Current problems in remote sensing of Earth from space]. 2012, vol. 9, no. 3, pp. 199-206. (In Russian).

Khakhinov V.V., Potekhin A.P., Lebedev V.P., Medvedev A.V., Kushnarev D.S., Shpynev B.G., Zarudnev V.E., Alsatkin S.S., Ratovsky K.G, Podlesny A.V., Bryn'ko I.G. Radio physical methods of diagnostics of the ionospheric disturbances generated by onboard engines of TCS Progress: algorithms, tools and results. Zhurnal radioelektroniki. Rossiiskaya nauchnaya konferentsiya "Zondirovanie zemnykh pokrovov radarami s sintezirovannoi aperturoi". Ulan-Ude, 06.09-10.09.2010. [J. Radio Electronics. Proc. the Russian Scientific Conference "Sounding of Terrestrial Covers Using Radars with the Synthesized Aperture. Ulan-Ude, 06.0910.09.2010]. 2010, p. 553-569. (In Russian).

Khakhinov V., Potekhin A., Shpynev B., Alsatkin S., Ratovsky K., Lebedev V., Kushnarev D. Results of complex radio sounding of ionospheric disturbances generated by the transport spacecraft Progress onboard thrusters. Proc. $30^{\text {th }}$ URSI General Assembly and Scientific Symposium. 2011. Available at: http://www.ursi.org/proceedings/procGA11/ursi/ HP2-15.pdf (accessed 12 May 2017).

Khakhinov V.V., Potekhin A.P., Lebedev V.P., Kushnarev D.S., Alsatkin S.S. Some results of Plasma-Progress and Radar-Progress active space experiments. Vestnik Sibirskogo gosudarstvennogo aerokosmicheskogo universiteta im. akade-mika M.F. Reshetneva [Bull. M.F. Reshetnev Siberian State Space University]. 2013, special iss., vol. 5, no. 51, pp. 160 162. (In Russian).

Khakhinov V.V., Shpynev B.G., Lebedev V.P., Kushnarev D.S., Alsatkin S.S., Khabituev D.S. Radio sounding of ionospheric disturbances generated by exhaust streams of the transport spacecraft Progress engines. Proc. PIERS-2012. Moscow, 2012, pp. 1168-1171.

Klunko E.V., Eselevich M.V., Tergoev V.I. Progress cargo spacecraft observed with the AZT-33IK optical telescope. SolarTerr. Phys. 2016, vol. 2, no. 3, pp. 22-31.

Kunitsyn V.E., Nesterov I.A., Shalimov S.L. Japan megathrust earthquake on March 11, 2011: GPS-TEC evidence for ionospheric disturbances. J. Experimental and Theoretical Phys. Lett. (JETP Lett.). 2011, vol. 94, no. 8, pp. 616-620.

Lebedev V.P., Khakhinov V.V., Kushnarev D.S., Podlesny A.V., Garkusha V.I. Radiophysical effects of spacecraft engine burn. Trudy XXIV vserossiiskoi konferentsii po rasprostraneniju radiovoln [Proc. $24^{\text {th }}$ National Conference "Propagation of Radio Waves". Irkutsk. June 29 - July 5 2014]. 2014, vol. 1, pp. 60-66. (In Russian).

Lejeune S, Wautelet G, Warnant R Ionospheric effects on relative positioning within a dense GPS network. GPS Solutions. 2012, vol. 16, no. 1, pp. 105-116.

Lipko Yu.V., Pashinin A.Yu., Rakhmatulin R.A., Khakhinov V.V. Geomagnetic effects caused by rocket exhaust jets. Solar-Terr. Phys. 2016, vol. 2, no. 3, pp. 43-55.

Liu J.Y., Lin C.H. Ionospheric solar flare effects monitored by the ground based GPS receivers: theory and observation. J. Geophys. Res. 2004, vol. 109, A01307.

Perevalov A.A., Perevalova N.P. The control and data acquisition with dual-frequency GNSS receiver Javad Delta via interfaces USB and RS-232 in interactive and batch modes in the Linux operating system. Certificate of State Registration of Program for Computer № 2016613942. 12.04.2016. (In Russian).

Perevalova N.P., Afraimovich E.L., Voeykov S.V., Zhivetiev I.V. Parameters of large scale TEC disturbances during strong magnetic storm on October 29, 2003. J. Geophys. Res. 2008, vol. 113, A00A13. DOI: 10.1029/2008JA013137.

Perevalova N.P., Voeykov S.V., Yasyukevich Yu.V., Ishin A.B., Voeykova E.S., Sankov V.A. Investigation into ionospheric disturbances caused by the earthquake of 11 March 2011 in Japan, using GEONET data. Sovremennye problemy distantsionnogo zondirovaniya Zemli iz kosmosa [Current problems in remote sensing of Earth from space]. 2012, vol. 9, no. 3, pp. 172-180. (In Russian).

Prikryl P., Jayachandran P.T., Mushini S.C., Pokhotelov D., MacDougall J.W., Donovan E., Spanswick E., St.-Maurice J.-P. GPS TEC, scintillation and cycle slips observed at high latitudes during solar minimum. Ann. Geophys. 2010, vol. 28, pp. 1307-1316.

Seismoionosfernye i seismoelektromagnitnye protsessy $v$ Bajkal'skoi riftovoi zone. Ed. Zherebtsov G.A. [Seismoionospheric and Seismoelectromagnetic Processes in the Baikal Rift Zone. Ed. Zherebzov G.A.]. Novosibirsk, SB RAS Publ., 2012. 304 p. (In Russian).

Shimeis A., Borries C., Amory-Mazaudier C., Fleury R., Mahrous A.M., Hassan A.F., Nawar S. TEC variations along an East Euro-African chain during 5th April 2010 geomagnetic storm. Adv. Space Res. 2015, no. 55, pp. 2239-2247.

Shpynev B.G., Alsatkin S.S., Khakhinov V.V., Lebedev V.P. Investigating the ionosphere response to exhaust products of Progress cargo spacecraft engines on the basis of Irkutsk incoherent scatter radar data. Solar-Terr. Phys. 2017, vol. 3, no. 1 , pp. 114-127.

Spogli L., Alfonsi L., Cilliers P.J., Correia E., Franceschi G., Mitchell C.N., Romano V., Kinrade J., Cabrera M. A. GPS scintillations and total electron content climatology in the southern low, middle and high latitude regions. Annals of Geophys. 2013, vol. 56, no. 2, R0220.

Tsugawa T., Saito A., Otsuka Y., Nishioka M., Maruyama T., Kato H., Nagatsuma T., Murata K.T. Ionospheric disturbances detected by GPS total electron content observation after the 2011 Tohoku Earthquake. Earth, Planets and Space. 2011, vol. 63, no. 7, pp. 875-879.

Yasyukevich Y.V., Voeikov S.V., Zakharov V.I., Kunitsyn V.E. The response of the ionosphere to the earthquake in Japan on March 11, 2011 as estimated by different GPS-based methods. Geomagnetism and Aeronomy. 2015, vol. 55, no 1, pp. 108-117.

Zakharov V.I., Yasyukevich Y.V., Titova M.A. Effect of magnetic storms and substorms on GPS slips at high latitudes. Cosmic Res. 2016, vol. 54, no 1, pp. 20-30.

Zherebtsov G.A., Perevalova N.P. Ionospheric response to a rocket launch from the Vostochnyi Cosmodrome. Doklady akademii nauk. Nauki o Zemle [Doklady Earth Sciences]. 2016, vol. 471, part 2, pp. 1280-1283.

Как ичитировать эту статью

Ишин А.Б., Перевалова Н.П., Воейков С.В., Хахинов В.В. Первые результаты регистрации ионосферных возмущений по данным сети SibNet приемников ГНСС в активных космических экспериментах. Солнечно-земная физика. 2017. Т. 3, № 4. С. 82-92. DOI: $10.12737 /$ szf-34201708. 